УДК $390(=471.344)$

ББК $60.56 ; 63.4 ; 63.5$

\title{
Автомобиль как маркер идентичности: исторические аспекты
}

\author{
B.B. Медведев
}

Сургутский государственный педагогический университет (Сургут, Россия)

\section{Car as a Marker of Identity: Historical Aspects}

\author{
V.V. Medvedev
}

Surgut State Pedagogical University (Surgut, Russia)

Статья посвящена исследованию новых аспектов демонстрации идентичности в контексте автомобильной культуры и отражает тенденции и стремление автовладельцев акцентировать внимание на идентичности/идентичностях, этническом происхождении, религии, месте рождения и проживания. Автомобиль представлен в качестве объекта, рассматриваемого с позиции семиотического подхода и выполняющего маркирующую роль. На основании опубликованных отечественных и зарубежных работ, а также наблюдений автора автомобиль охарактеризован как маркер идентичности/идентичностей в контексте этничности, религии и территории. Конкретные примеры способствуют пониманию возможностей знаково-символического маркирования для поиска соотечественников в городском пространстве и автомобильном потоке, форм привлечения внимания к автомобилю и лично водителю, «вызова» другим участникам процесса движения.

Проведенное исследование позволяет сделать выводы о том, что визуализация самосознания водителя на корпусе автомобиля и наличие в салоне маркирующих предметов регулярно демонстрируют идентичность / идентичности автовладельца. Потребность в самоидентификации с более широкой общностью существовала всегда, поскольку придавала чувство уверенности и стабильности. Отождествление себя с определенным регионом / городом / сельским поселением конкретизирует связь не только с территорией как местом рождения или предыдущего проживания, но и семьей, широким кругом родственников и друзей, т.е. всем, чем человек дорожит и что для него действительно важно. В более широком восприятии - это отождествление себя с этнической группой/народом, самоопределение индивида как части этнического сообщества.

Ключевые слова: автомобиль, идентичность, маркер, самосознание, этничность, религия, территория.
This article is devoted to the study of new aspects of the demonstration of identity in the context of automotive culture and reflects the tendencies and the desire of car owners to focus on identity / identities, ethnic origin, religion, place of birth and residence. The article presents a car as an object viewed from the perspective of a semiotic approach and fulfilling a marking role. Based on the published domestic and foreign works, as well as the author's observations, the car is characterized as a marker of identity / identities in the context of ethnicity, religion and territory. Specific examples contribute to the understanding of the possibilities of symbolic and symbolic marking to search for compatriots in urban space and car traffic, forms of attracting attention to the car and the driver personally, «calling» to other participants in the movement process.

The conducted study allows to draw conclusions that the visualization of the driver's self-awareness on the vehicle body and the presence of marking objects in the cabin regularly demonstrate the identity / identity of the car owner. The need for self-identification with a broader community has always existed, because it gave a sense of confidence and stability. Identification with a certain region / city / rural settlement concretizes the connection not only with the territory, as place of birth or previous residence, but also a family, a wide range of relatives and friends, i.e. everything that a person values and what is really important. In a wider perception is identification with an ethnic group / people, selfdetermination of the individual as part of an ethnic community.

Key words: car, identity, marker, self-consciousness, ethnicity, religion, territory. 
Движение, образ дороги и возможности транспортных средств на протяжении многих лет привлекают к себе внимание антропологов, философов, социологов, фольклористов. Тематика уверенно приобрела характер интердисциплинарности. Дж. Урри неслучайно делает акцент на вопросах движения, являющихся «ключевыми для жизни большого числа людей и для функционирования множества < .. > организаций» $[1$, с. 71].

Автомобиль в мировоззрении современного человека, «отношения» между автовладельцем и его «железным другом», «обживание» внутреннего пространства салона с целью моделирования знакомой «домашней» обстановки, а также внешний тюнинг - проблемы, достаточно активно обсуждаемые на страницах периодических изданий. Надписи, олицетворяющие «имена» автобусов, бытовавшие в Коста-Рике и Панаме, стали предметом исследовательской практики Ф. Голли [2, p. 58-60]. Обращаясь к моделям британской и индийской автомобильной культуры, Т. Эденсор изучает роль и предназначение культовых автомобильных марок, характеристики вождения и повседневность автовладельцев [3, p. 101-120].

Подобный подход применяет Ю. Алам, рассматривающий автомобиль как объект меж-/ внутрирасового/этнического различия и на примере пакистанцев Брэдфорда (Англия), утверждающий, что марка, модель и внешняя эстетика автомобиля позволяют определить этническую принадлежность его владельца [4, р. 284-301]. Совместная работа Н. Клокер, С. Тул, А. Тиндейл и С.-М. Керр посвящена автомобильной культуре разных этнических групп из числа горожан Сиднея и Вуллонгонга (Австралия). Авторы обращают внимание на то, что городские жители из числа иностранцев, мигрантов и некоторых этнических меньшинств владеют меньшим числом автомобилей, используя их реже, чем австралийцы и англоавстралийцы. Сделан акцент на существовании различных транспортных культур и этнически разнообразном транспортном поведении, значимом при планировании и выработке стратегий транспортной политики [5, р. 393-405].

Статья Д.Ф. Мищенко презентует результаты авторских наблюдений за многочисленными надписями и изображениями, встречающимися на общественном транспорте Абиджана - крупнейшего города Кот-д'Ивуара [6, с. 155-169; 7, р. 461-478]. Т.Б. Щепанская, рассматривая автомобиль в контексте антропологии движения, предлагает читателям задуматься над вопросами соотношения вещественных и невещественных аспектов функционирования предмета, вещественности и мобильности, интерпретации знаково-символических форм [8, с. 53-66]. Размышления о развитии автомобильной культу- ры в XX-XXI столетиях и ее влияния на представления о пространстве нашли отражение в публикации А.3. Исаханян [9, с. 166-173].

Автомобиль как неотъемлемый компонент повседневности занимает в нашем сознании значительное место - это не просто материальный объект, а «спутник» своего владельца, отражающий его образ жизни, мировоззрение и предпочтения. Другими словами, автомобиль - это «Я» владельца $[10$, c. 125$]$. Он становится неким интимным, приватным пространством для водителя, сформированным в соответствии с личными предпочтениями [9, с. 171]. Отождествление автовладельца с конкретной группой, позиционирование себя как части этнического, профессионального, территориального или культурного сообщества позволяют надписи, рисунки, аэрография и интерьер автомобиля, т.е. его корпус и салон следует воспринимать в качестве средств коммуникации. Например, женщины за рулем, стремясь оградить себя от агрессии со стороны водителей-мужчин, приклеивают на автомобиль «каблучки» и другие «женские» знаки, привлекая к себе дополнительное внимание [11, c. 212]. Безусловно, автомобиль не стоит расценивать только как средство передвижения, поскольку это особое, приватное пространство водителя, наделенное собственной аутентичностью и значимостью $[9$, с. 171].

Стремление «освоить» личный автомобиль выражается не только в регулировании сидения или технической инновации, но и символическом (можно сказать, что отчасти даже «сакральном») «обживании» объекта - как в отношении кузовной части, так и пространственной среды салона. В этом стремлении в числе проявляющихся идентичностей среди конкретных визуальных образов нельзя оставить без внимания этническую самоидентификацию и самосознание. Визуализация этничности на кузове автомобиля, ветровом стекле или в салоне примечательна еще и в связи с тем, что в научных кругах нередко разгораются бурные дискуссии об этничности и звучит тезис об утрате ее значения в условиях глобализации [12, с. 430-442]. В данном случае можно наблюдать, как этничность находит самовыражение, сохраняя устойчивый тренд, и насколько органично она включена в политику идентичности, представляющую собой совокупность практических и символических действий, направленных на формирование, поддержание и признание конкретной идентичности [13, с. 6].

Буквально 100-150 лет назад этническая принадлежность человека могла быть определена с первого взгляда - достаточно было приглядеться к одежде, демонстрирующей традиционный костюм конкретного народа. Естественно, мужской костюм был подвержен изменениям в первую очередь, что обуслов- 


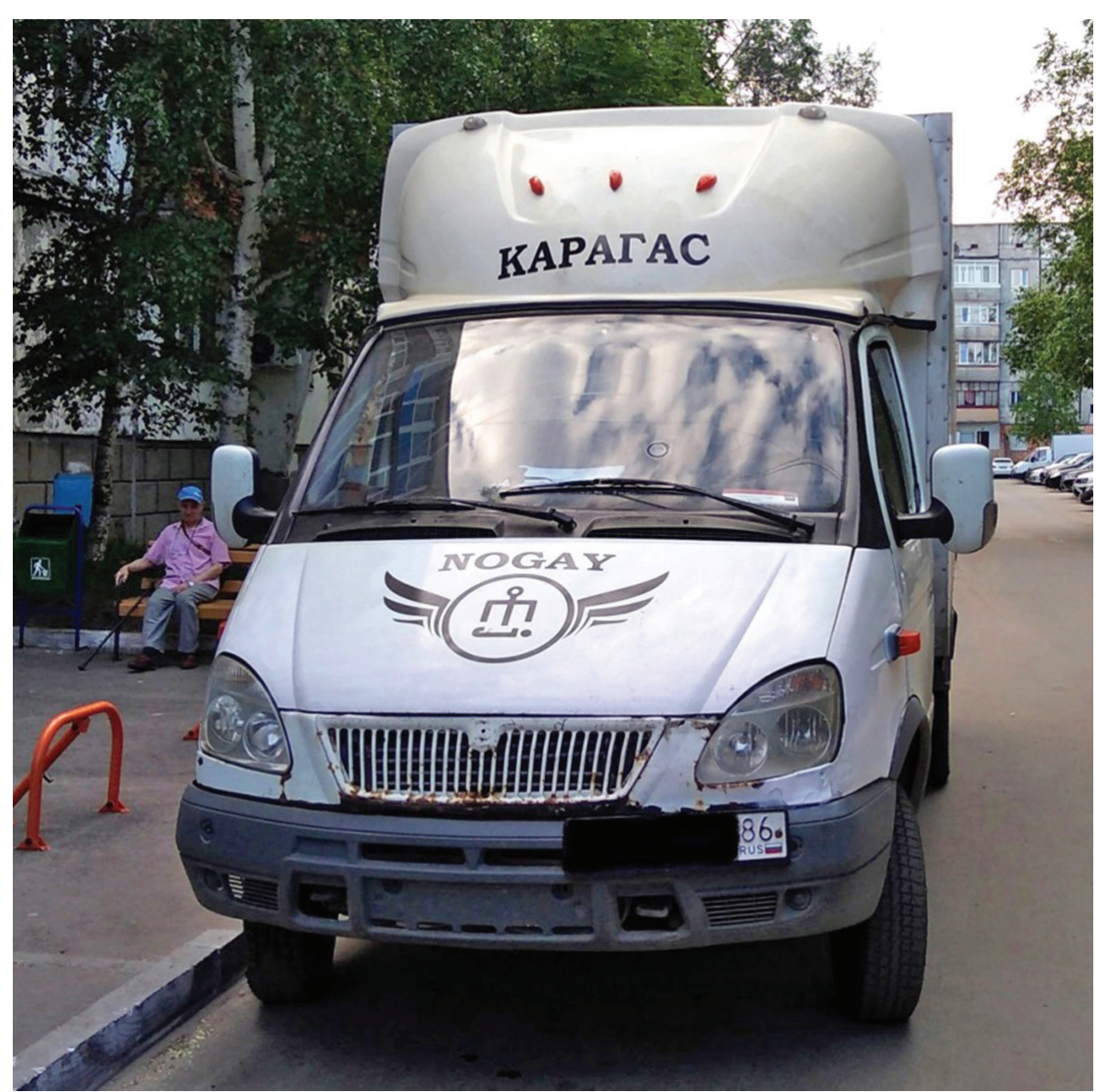

Рис. 1. Автомобиль, принадлежащий ногайцу, демонстрирующий этничность (ХМАО-Югра, Сургут, 2018 г.). Фото автора

лено работой на заводах, в крупных сельских центрах и городах. Городской образ жизни активно проникал в сельскую среду, вытесняя традиционную одежду из повседневного обращения.

В наши дни подобный костюм или конкретнее его элементы мы наблюдаем на праздниках и мероприятиях, транслирующих традиционную культуру народа / народов России. Одежда, как и ее многочисленные составляющие, уже не презентуют этничность, но возникают иные формы, наглядно демонстрирующие самосознание и этническую, конфессиональную или территориальную идентификацию. Таким образом, перед нами новые, ранее не известные и не востребованные материальные формы проявления идентичности. Несмотря на размещение знаково-символических маркеров на автомобиле, на него они не проецируются, а служат маркерами водителя, отражая его сознание [8, с. 59].

Базовыми материалами для написания статьи послужили наблюдения автора, осуществленные на улицах города Сургута Ханты-Мансийского автономного округа - Югры в 2016-2019 гг. Изложенные в статье размышления представлены с позиции семиотического подхода, позволяющего, по словам С.В. Соколовского, «идею рассмотрения культуры как текста, а вещи - как знака» $[14$, с. 7]. В нашем случае автомобиль воспринимается в качестве семиотически значимого объекта, надписи и наклейки которого позволяют «прочитать» значения, целенаправленно приписываемые объекту [8, с. 59-60].

Этничность. Современный автомобиль уверенно можно сравнить с настоящим этнокультурным объектом, позволяющим выразить самосознание автовладельца и продемонстрировать идентичность. В англоязычной литературе подобное явление, т.е. знаково-символическое маркирование автомобиля, известно как «вегикулярное искусство» или «вегикулярный маркер», а для русскоязычного текста, по предложению Т.Б. Щепанской, необходимо использовать термин «автомаркер» [15, с. 295-296].

Изображения, аэрография и наклейки могут быть нанесены на ветровое стекло и кузов, что мы и наблюдаем на автомобиле ГАЗель, владельцем которого является ногаец (рис. 1). 
Во-первых, перед нами этноним «nogay» - «ногайцы», свидетельствующий о самоидентификации автовладельца и отождествления себя с данным народом. Во-вторых, слово «карагас». «Карагас» - это ойконим, аул Ногайского района Дагестана, являющийся моноэтничным ногайским поселением. Возможно, это видоизмененная форма одной из этнографических групп ногайцев - карагашей, употребляющих в качестве эндоэтнонима сочетание карагаш ногай. В-третьих, родовой знак - тамга «печать». Именно подобное изображение нередко используется ногайцами в качестве символа, олицетворяющего историческое и культурное наследие народа. Тамга заключена в круг и дополнена крыльями, что связано с изображением «коьк боьри» - «небесного волка»/«крылатой волчицы», ставшего этническим символом ногайцев в 90-х гг. прошлого столетия. Его воспринимают в качестве знамени народа. С изображением связаны многочисленные исторические сюжеты. Подобные знаки позволяют представителям данной этнической группы «находить» друг друга в новом пространстве, идентифицировать при встрече и выстраивать взаимоотношения [16].

Среди ногайцев наибольшей популярностью пользуется круглая наклейка, на которой центр синего/голубого поля занимает черный рисунок «коьк боьри» с золотыми контурами. Круг обрамлен золотым полем, отображающим тамги ногайских родов. Подобные наклейки, как правило, ногайцы наносят на задние ветровые стекла автомобилей, чтобы в движущемся потоке их можно было разглядеть. Аналогом служат самостоятельные изображения тамг на стеклах. По этим же наклейкам в отдельных частях города и конкретных кварталах наблюдаем сосредоточение ногайских семей, проживающих группами. Такие изображения не только этнически идентифицируют автовладельца, но и позволяют найти соотечественников, возможно, ради общения или с просьбой о помощи.

Не менее выразительным проявлением этнического самосознания на автомобильном стекле может послужить еще один пример, но уже идентифицирующий гагаузов. Надпись «gagauz» - «гагауз», окаймляющая изображение волчьей головы - этнического и культурного символа народа. Для традиционной культуры гагаузов волк является животным, с которым связаны многие предания, обрядовые действа и праздники.

Подобная форма этнической самоидентификации, как и ее демонстрация перед обществом в наши дни уже не новация, а вполне устоявшееся явление. Например, новостная лента 2013 г., освещающая жизнь города Казани и ее горожан, содержит заметку под названием «В Казани появились автомобили с надписями Мишарин». Эксперты, на мнения которых опирается автор новости, расценивают данный факт как акцент мишарей на собственной этнической принадлежности, считающих себя «высшим сортом среди всех татар» и свидетельствующим о самосознании этнической группы, выражающимся автомаркерами «Мишар», «Мишарин» или «Мишарка». Именно таким путем мишари заявляют о том, что «не стремятся к ассимиляции с казанскими татарами, отличают себя от остальных татар» [17].

Не менее интересный пример, характеризующий процессы этнической идентификации среди калмыков, предлагает следующая новость: «В Калмыкии на автомобили наносят знаки этнической принадлежности». Номера автомобилей дополняют специальные рамки, в которых записаны этнические подразделения калмыцкого народа - торгоуты / торгуты, дербеты / большие дербеты / малые дербеты / дервюды, хошеуты, олеты / элеты, бузавы и др. (рис. 2).

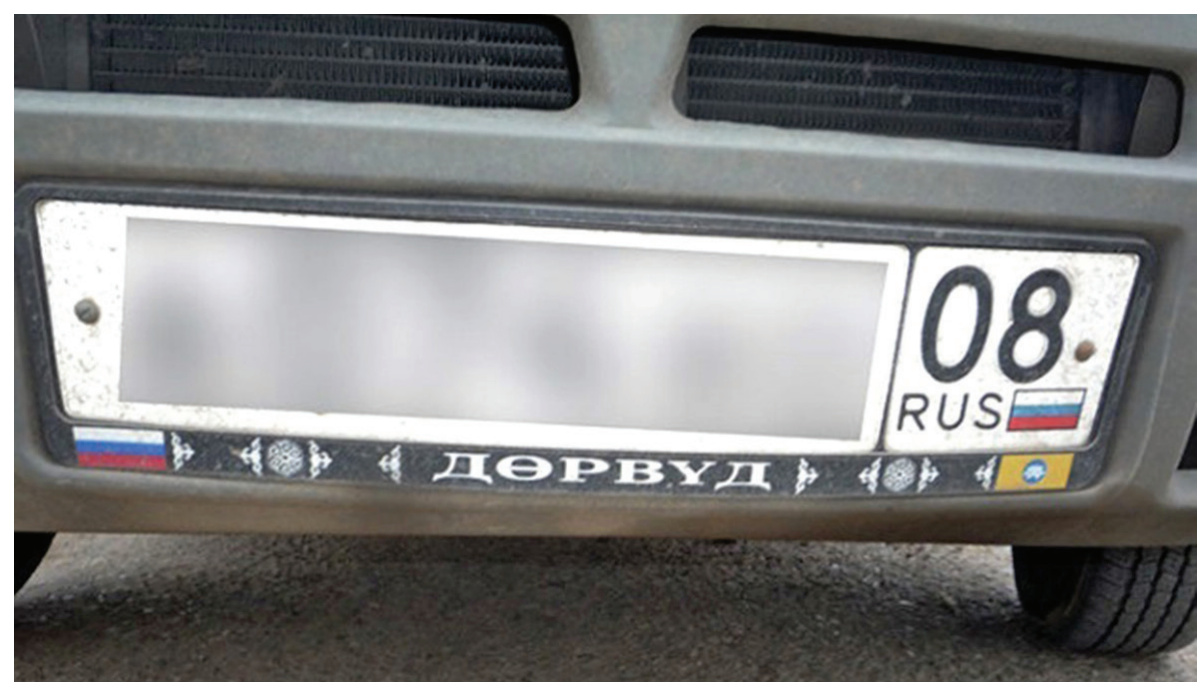

Рис. 2. Номер, дополненный специальной рамкой, содержащей название этнического подразделения калмыков [18] 
Востребованность такого рода продукции среди калмыков подчеркивают отрывки интервью, представленные в статье: «Когда в городе в продаже появились рамки для номеров, где были изображены флаги России и Калмыкии, я был рад. Еще больше мне понравилось, когда стали выпускать рамки с названиями рода. Я не националист, но хочется показать гордость за свой народ. Сразу повесил себе - дервюд». Рамки с подобными дополнениями мотивируют людей задуматься над вопросом по поводу своей принадлежности к конкретному роду. Так, один из автовладельцев по этому поводу рассуждает следующим образом: «Папа мой торгоут, мама - батутка. Зная о заслугах обоих родов, до сих пор не могу определиться со своей принадлежностью. У меня нет на машине никакой родовой таблички» [18].

Подобный тренд пользуется большой популярностью среди автолюбителей и широко представлен на улицах Сургута, причем отражает он не только этническую принадлежность (например, надписи под номером «Абаза», «Татарская мафия»), но и государственную («Российская Федерация», «Россия», «Russia», «Армения», «Kazakhstan»), а также peгиональную («Северный Кавказ», «Дагестан», «Калмыкия») и локальную («Moscow», «Сургут», «Екатеринбург») идентификацию. Нередко надписи сопровождает изображение флагов субъектов Российской Федерации. Естественно, у калмыков рядом с надписью «Дервюд» - флаг Калмыкии, у татар - «Татарская мафия» и флаг Татарстана, номера с надписью «Дагестан» дополнены изображением флага республики.

Для легковых, общественных и грузовых автомобилей, встречающихся на российских дорогах, в том числе на улицах Сургута, надписи, слоганы и наклейки являются вполне обыденными и воспринимаются как нечто естественное, хотя и привлекающее к себе внимание. Примечательно, что, по наблюдениям Д.Ф. Мищенко, в Абиджане изображения и надписи характерны только для общественного транспорта и в гораздо меньшей степени - для грузовых автомашин. По мнению автора, «надписи и изображения на транспортном средстве - это атрибут профессии, практика, распространенная в границах профессионального сообщества» [6, с. 157].

Как правило, экстерьер грузовых автомобилей и микроавтобусов дополняют разнообразные надписи, но не только слова и слоганы, а полноценные предложения, подчеркивающие, в том числе, этничность. Надпись на автомобиле, зарегистрированном в Нижегородской области, на чувашском языке «Хамӑр ял турӑпа пӗрле» - «Земляки с Богом вместе». Иной пример - надпись по-марийски: «Виян лийже марий калык» - «Да здравствует марийский народ».
Размышляя над идентификационными процессами, в частности над этничностью, необходимо добавить, что роль индикатора реализовывает и музыка, звучащая в автомобиле. Именно в таком контексте Д.З. Моррис проанализировал технологическую и культурную трансформацию аудиосистемы в американском автомобильном звуке, поскольку технология начала применяться для утверждения идентичности [19, р. 326-353].

Религия. Символы и предметы, подчеркивающие конфессиональную принадлежность владельца автомобиля, могут быть представлены на его ветровом стекле или, что наблюдаем в большинстве случаев, внутри салона - на приборной панели и салонном зеркале заднего вида. Среди наклеек и изображений встречаются разные по форме и количеству концов кресты, ихтисы - монограммы имени Иисуса Христа, аллегорически представленные в виде рыбы, полумесяцы, изображения минарета мечети и надписи, выполненные на русском и арабском языках. Например, «Спаси и сохрани», «Господи, спаси и сохрани», «С Богом по всем дорогам», «Алла cakласын», т.е. надписи, конкретизирующие конфессиональную принадлежность автовладельца (см. рис. 3). Функциональное предназначение надписей подобного рода - охранительное, поскольку воспринимаются они в качестве апотропея и должны «помогать» в пути.

Целенаправленное акцентирование автовладельцем внимания на собственной религиозной принадлежности следует расценивать как прием самоидентификации [6, с. 160]. Необходимо понимать, что подобные надписи делают только в соответствии с личными пожеланиями владельца автомобиля.

Православная автомобильная атрибутика представлена подвесками, крестами, четками, «тройниками» (иконками для автомобилей Иисуса Христа, Богородицы, Святого Николая), наклейками освящения, берестой с молитвами водителя, двусторонними подвесками-иконками Богородицы, Спасителя и Святого Николая, а также многим другим. Среди икон для автомобиля распространены иконки «Святое семейство и Спаситель», «Казанская и Ангел Хранитель», «Спаситель и Семистрельная».

Православное духовенство позитивно оценивает стремление автовладельцев размещать религиозную символику в автомобилях, поскольку в данном случае такие изображения воспринимаются как иконы, стоящие в «красных углах» жилых домов, перед которыми можно перекреститься и прочитать молитву [20]. Интересный случай о совершении своеобразного обряда «крещения» автомобиля упомянут Т.Б. Щепанской. Водитель лесовоза из Андомского погоста Вологодской области, получив в эксплуатацию новый лесовоз, совместно с напарником «подарил» автомобилю три православных креста. Один крест 


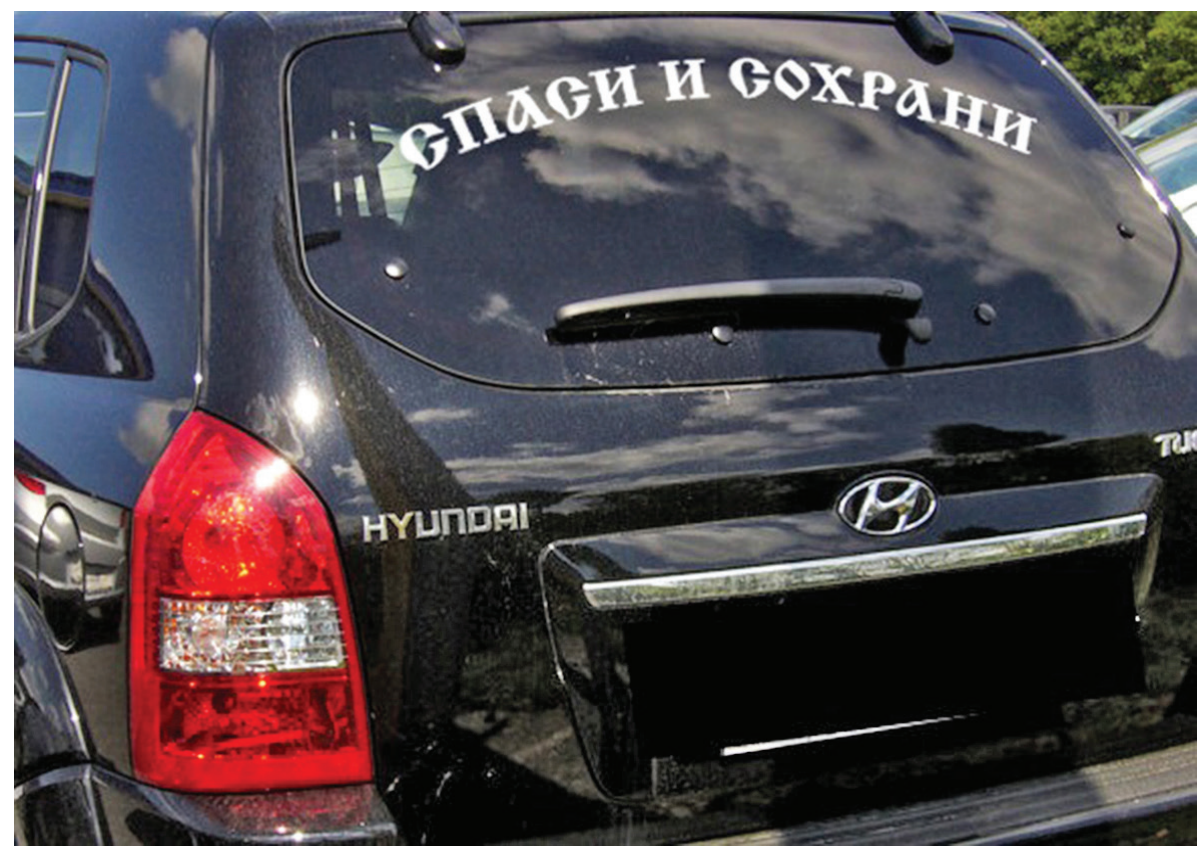

Рис. 3. Надпись «Спаси и сохрани» на ветровом стекле автомобиля (ХМАО-Югра, Сургут, 2017 г.). Фото автора

приобрел рассказчик, другой — напарник, а третий олицетворял крест уже самого автомобиля [21, с. 295].

Салон водителей-мусульман дополняют подвески («Тасбих», «Аллах»), четки/тасбих, Коран миниформата и разного рода предметы, содержащие аяты. Это могут быть, например, декоративные подушки. В некоторых случаях цитаты из Корана украшают боковые зеркала заднего вида. Особой популярностью пользуется так называемый «глаз Фатимы», известный также как «Голубой глаз», «Синий глаз», «Назар» и под иными названиями. Считается, что именно этот предмет защитит своего владельца от сглаза и болезни, а в данном случае - от дорожных неурядиц и аварийных ситуаций.

При такой внешней религиозности, необходимо подчеркнуть, что многие автовладельцы размещают предметы православного или мусульманского культа, не задумываясь над сакральным предназначением - своего рода это необходимые атрибуты, выполняющие роль апотропеев, что в принципе противоречит религиозным нормам. Как и надежда на покровительство со стороны Бога/Аллаха в сложной ситуации, такие предметы, обратившись к которым можно произнести слова молитвы, попросить благополучия в пути и удачной дороги, воспринимаются лишь небольшим числом водителей.

Можно констатировать, что православная и мусульманская атрибутика внутри салона или на внешнем корпусе автомобиля играет двойную и совершенно противоречивую роль. В первом случае религиозные символы и предметы реализуют маркирующую функцию, т.е. действительно акцентируют внимание на кон- фессиональной принадлежности автовладельца и его семьи в целом, если мы подразумеваем «семейный автомобиль». Во-вторых, это уже достаточно устойчивая тенденция, представляющая собой некую «дань моде», поскольку в таком случае религиозная символика воспринимается как предмет из серии фэн-шуй. Нередко можно наблюдать как православная атрибутика и подвески фэн-шуй вместе расположились на салонном зеркале заднего вида. В этом отношении водители-мусульмане более внимательно и разборчиво относятся к религиозной атрибутике личного автомобиля.

Территория. Одним из направлений, заслуживающих внимания исследователя и достаточно широко представленных на автомобилях, является территориальная/региональная/локальная идентификация. Можно говорить об автомобиле и в контексте формирования государственного/общенационального самосознания, поскольку многие автовладельцы, особенно молодые водители, охотно наносят на кузов наклейки с изображением двуглавого орла, символизирующего Россию. Помимо корпуса, официальные символы разных субъектов Российской Федерации могут находиться на стеклах. Коллекция автора содержит фотографию заднего ветрового стекла Lada 110, дополненную наклейкой, представляющей собой по форме и рисунку герб Республики Дагестан.

Гербовые эмблемы подчеркивают территориальную локацию и государственное/национальное самосознание. Для достижения цели автовладелец украшает стекло автомобиля гербом своей страны. Дополнительная визуализация осуществляет в данном случае выражение самосознания. 
На городских улицах регулярно наблюдаются автомобили с ветровыми стеклами, украшенными надписями, акцентирующими внимание на населенных пунктах, в которых родились или ранее проживали автовладельцы, а в ряде случаев и группа людей, если речь идет о грузовом автомобиле и совместной профессиональной деятельности. Примером этого послужат такие надписи, как «Орта-Тюбе» - село Ногайского района Республики Дагестан с преобладающим ногайским населением (рис. 4), «Чубутла» - аварское поселение Ботлихского района Республики Дагестан, «Каракчикум» - населенный пункт в составе сельской общины им. Лахути Канибадамского района Согдийской области Республики Таджикистан.

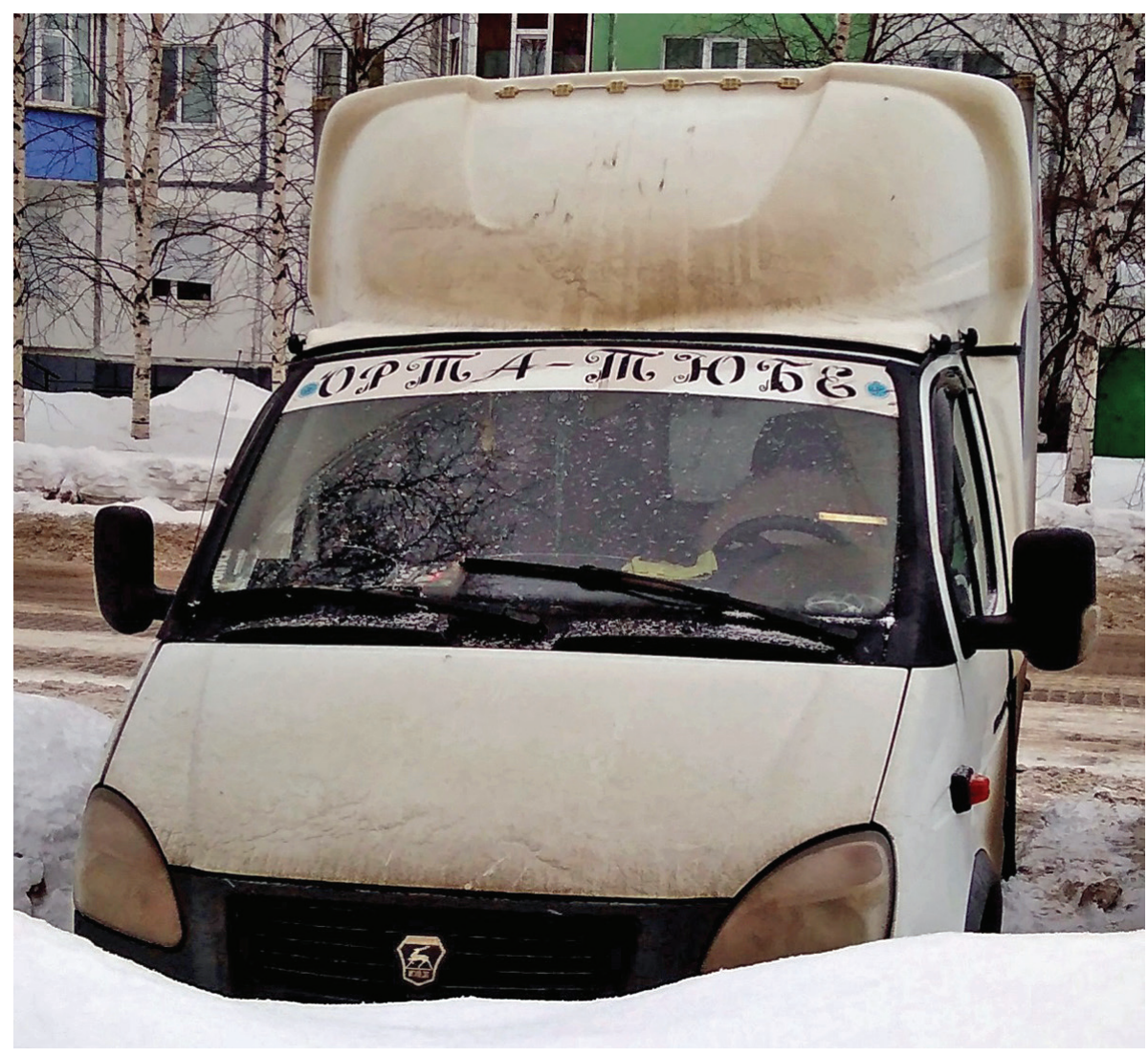

Рис. 4. Надпись «Орта-Тюбе» на ветровом стекле автомобиля (ХМАО-Югра, Сургут, 2019 г.). Фото автора

Достаточно распространенной среди автовладельцев, особенно грузовых автомобилей, является тенденция размещения аналогичных территориальных / региональных надписей на русском и английском языках на ветровых стеклах, но подчеркивающих город или регион уже нынешнего проживания и работы. Это такие надписи как «Сургут», «Surgut», «Туumen», «Челябинск» и другие, а в более широком региональном значении - «Ugra», «Я*сибиряк».

Интерьер салона автомобилей дополняют разнообразные по формату вымпелы, флажки, фигуры и прочие визуальные образы, демонстрирующие официальную государственную или региональную символику. Естественно, государственные флаги, предметы цветов флага России и изображения ее герба отражают национальную самоидентификацию автовладельцев [8, с. 57].
Среди наблюдений автора необходимо выделить заслуживающий внимания пример - наличие в салоне автомобиля официальных символов/флагов двух государств - Армении и России. Своего рода это выражение «двойственности» в личной идентификации владельца. Человек, родившийся в Армении, но проживающий на протяжении многих лет в России, армянин по происхождению, твердо осознающий собственную этническую принадлежность, но уже не представляющий свою жизнь за пределами России и позиционирующий себя «русским» / россиянином. Возможно, именно такие внутренние «противоречия» находят отражение в подобной демонстрации как государственного / национального, так и этнического самосознания.

Автомобили, как и предметы, находящиеся внутри салона, по определению Т.Б. Щепанской, воспроизводят «домашние идентичности» и «дорожные идентичности» $[8$, с. 64]. Содержание статьи конкретизирует 
идентичности первой группы - этническую, религиозную и территориальную. Обсуждению в публикации подверглись и формы проявления национального сознания. Как маркер автомобиль способен проецировать и иные типы идентичностей - гендерную, профессиональную, семейную, военную (речь идет о родах войск в которых служил/служит автовладелец), спортивную (визуальные образы определенного вида спорта, команды), культурную, клубную и т.д.

Маркеры идентичности/идентичностей, представленные на автомобилях, делают возможным распознавание автовладельцев (в нашем случае - по этнической принадлежности, конфессии либо территории), моделирование стратегий поведения и предполагаемых форм взаимодействия.

Знаково-символическое маркирование автомобиля прежде всего служит реалиями повседневности пространства средних и крупных городов, представляющих полиэтничные и поликультурные сооб- щества. Жители таких локусов в большей степени испытывают дополнительную потребность в самовыражении вследствие иноэтничного окружения и регулярного кросс-культурного взаимодействия. Визуализация этничности, религиозной принадлежности и территориальной привязанности на корпусе или стекле автомобиля позволяют заполнить подобную лакуну в сознании автовладельцев.

Материалы данной статьи предоставили возможность посредством автомобиля рассмотреть и охарактеризовать особенности идентификационных процессов, наблюдаемые в пространстве этнически и конфессионально разнообразных городов (на примере Сургута как одного из центров Ханты-Мансийского автономного округа - Югры). Демонстрация конкретного типа идентичности / идентичностей водителями - это самовыражение, отождествление себя с конкретной группой (этнической / религиозной) и соотнесение с конкретной территорией.

\section{Библиографический список}

1. Урри Дж. Мобильности / пер. с англ. А.В. Лазарева, вступ. статья Н.А. Харламова. М., 2012.

2. Golley F. Bus Names in Costa Rica // Wester Folklore. 1978. Vol. 37(1).

3. Edensor T. Automobility and National Identity // Theory, Culture \& Society. 2004. Vol. 21. № 4-5.

4. Alam Y. Automatic Transmission: Ethnicity, Racialization and the Car // Identities: Global Studies in Culture and Power. 2018. Vol. 25, № 3.

5. Klocker N., Toole S., Tindale A., Kerr S.-M. Ethnically Diverse Transport Behaviours: an Australian Perspective // Geographical Research. 2015. Vol. 53, № 4.

6. Мищенко Д.Ф. Надписи на такси в Абиджане (Котд'Ивуар) // Антропологический форум. 2015. № 24.

7. Wa-Mungai M. Hidden \$Centz: Rolling the Wheels of Nairobi Matatu // Les paradoxes d'une ville fragmentee. Paris, 2006.

8. Щепанская Т.Б. Движение и вещь: опыты чтения автомобиля в потоке // Этнографическое обозрение. 2016. № 5.

9. Исаханян А.З. Автомобильная культура в контексте современных концепций пространства // Вестник Томского гос. ун-та. Серия: Философия. Социология. Политология. 2016. № 4(36).

10. Корниленко Ж.В. Собственность как воплощение символического капитала (на примере автомобиля) // Вестник Волгоградского государственного университета. Серия 7: Философия. Социология и социальные технологии. 2016. № 1(31).

11. Ростова А.В. Способы конструирования идентичности автолюбителей: гендерные аспекты // Гражданское общество в России: состояние, тенденции, перспективы. 2015. № 1(4).
12. Дробижева Л.М. Этничность в современном обществе: новые подходы, старые мифы, социальные практики // Вестник Института социологии. 2010. № 1.

13. Тишков В.А. Междисциплинарный взгляд на историческую память и идентичность // Историческая память и российская идентичность. М., 2018.

14. Российская антропология и «онтологический поворот». Вып. 2. М., 2017.

15. Щепанская Т.Б. Вегикулярные маркеры и социальная коммуникация в «потоке» // Российская антропология и «онтологический поворот». Вып. 2. М., 2017.

16. Долгих М. Крылатая волчица // Национальный акцент. URL: http://nazaccent.ru/content/2185-krylatayavolchica.html.

17. В Казани появились автомобили с надписями Мишарин // Regnum. Информационное агентство. URL: https://regnum.ru/news/1614798.html.

18. В Калмыкии на автомобили наносят знаки этнической принадлежности // Medform. Самое интересное. URL: http://medform.net/12442-v-kalmykii-na-avtomobilinanosyat-znaki-etnicheskoy-prinadlezhnosti.html.

19. Morris D.Z. Cars with the Boom: Identity and Territory in American Postwar Automobile Sound // Technology and Culture. 2014. Vol. 55. № 2.

20. Как и какие иконы размещать в автомобиле // Bigpicture.ru. Новости в фотографиях. URL: https:// bigpicture.ru/?p=592952.

21. Щепанская Т.Б. Диалоги с вещами: конструирование виртуального партнера в рамках инструментальной деятельности // Вестник Челябинского гос. ун-та. Серия: Филология. Искусствоведение. 2011. № 24(239). Вып. 57. 